\title{
What Executives Can Learn From Bono
}

\author{
Francis Petit, Fordham University, USA
}

\begin{abstract}
The purpose of this research is to determine what executives can learn from Paul David Hewson (aka Bono). To determine this information, a historical study of Bono's life was conducted with the hopes of uncovering key learning points and takeaways for executives. The main findings of this study indicate that there are various lessons executives can learn from Bono's unconventional voyage to stardom and power. The results of this exploratory study can potentially ignite increased research on Bono's journey and what executives and corporate America can learn from this musician from Dublin.
\end{abstract}

Keywords: Bono; U2; Executive Development; Global Brand; Social Responsibility

\section{INTRODUCTION}

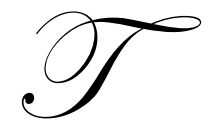

hroughout time, business students, professionals and aspiring executives have been studying the lives and decision making processes of powerful business tycoons and leaders in the hopes of learning and applying key information from their successes. During this period, biographies have been written and documentaries have been made outlining key learning points from their lives. In many cases, these successful professionals have traveled a traditional journey (i.e. Business School to eventually CFO to CEO). In other cases, a non traditional journey has been taken.

With this as a backdrop, the purpose of this research is to study the life of Mr. Paul David Hewson (aka Bono). Bono, the lead singer and spokesperson of $U 2$, is an individual who has achieved tremendous success and influence around the globe yet has traveled a journey that is quite different than anyone else.

For the purposes of this study, we are defining the term "executive" as a global thinker and leader of influence who not only adds tremendous value and success to an organization but who also is a key player within an industry. Bono certainly fits that definition when presented in this manner.

More specifically, Bono is the lead singer and spokesperson for the Irish rock band $U 2$. According to the $U 2$ official website, the band has been very successful "crafting music" as can be seen from the twenty two (22) Grammy Awards they have received throughout their thirty plus year history including "Best Rock Duo or Group", "Album of the Year", "Record of the Year" and "Best Rock Album". U2 has also been named "Band of the Year" by numerous publications and has also received a host of other awards including Meteor, BRIT, Q, Juno, AMA and ASCAP. U2 was also inducted into the Rock and Roll Hall of Fame in 2005.

In addition, $U 2$ has achieved tremendous financial success throughout the course of their existence. The following two examples are quite telling of this success. Rolling Stones Magazine, during the past decade, has ranked $U 2$ as the second highest grossing band of the decade (behind the Rolling Stones) as well as being the top concert grossing band in 2009. (Petit, 2010). In addition, Billboard Magazine has reported that U2 earned approximately $\$ 250$ million in 2005. ("U2 Tops Billboards Money Maker’s Chart, January 20, 2006). Overall, these indicators are apparent and significant.

Bono has also made a name for himself "beyond the music" for being a crusader for social justice and humanitarian issues. (i.e. famine relief, debt forgiveness, AIDS, Anti-Apartheid and disaster relief). Examples of his efforts can be seen by his work as a board member of Elevation Partners as well as co-founding DATA, EDUN, One Campaign and Product Red. His efforts in this area have earned him a host of recognition including being named 
Time Magazine's Persons of the Year in 2005 (with Bill and Melinda Gates) as well as being nominated for a Nobel Peace Prize, receiving Honorary Knighthood by Queen Elizabeth II and meeting with world leaders to discuss such issues including Pope John Paul II, George W. Bush, Paul O'Neill and Paul Martin. Bono has also lectured at Harvard's John F. Kennedy School of Government and has also addressed the World Economic Forum in Davos. (Petit, 2010).

In addition to his work with $U 2$ and with social and humanitarian causes, Bono has also collaborated with musical legends including Frank Sinatra, Luciano Pavarotti, Johnny Cash, Roy Orbison, Bob Dylan, Tony Bennett and Bruce Springsteen.

As one can see, Bono has achieved tremendous success as a member of $U 2$, as an individual musician/performer as well as a humanitarian.

In general, this research began with a thorough analysis of the life of Paul David Hewson and the decisions he has made. The goal of this study was to uncover any key points that executives can learn from Bono's untraditional journey to stardom, fame and influence. The initial hypothesis of this study was that executives can certainly learn from the Bono story. Interestingly, the extent of this learning was not fully realized until the study was completed.

\section{LITERATURE REVIEW}

Very little, from an academic perspective, has been written on Bono. Harvard Business School in 2009, published an academic case, Bono and U2 (Koehn, Miller and Wilcox, July , 2009) which is a comprehensive historical analysis of $U 2$ from its formation to its current state. In 2010, "What Executives Can Learn from U2: An Exploratory Study" (Petit) was published in the Review of Business and Finance Case Studies. This article analyzes the $U 2$ story and develops key takeaways executives can learn on how this "mega brand" was built.

Beyond these specific examples, there exists substantial literature on Bono and $U 2$ over the past twenty five (25) plus years through periodicals, interviews and performance reviews. In addition, information on Bono and his band mates can also be found via interviews and television programming now easily accessible on http://www.youtube.com. Furthermore, a feature concert film, Rattle and Hum, directed by Phil Jaonou and produced by Michael Hamlyn, was released in 1988 starring the members of $U 2$. While this film was not a commercial success, it documents the band during the Fall 1987 Joshua Tree Tour which is one of the most successful tours within the band's history. (Rattle and Hum, 1988).

It should also be noted that various biographies and commentaries have been written on $U 2$ and their music. Some of these works, most notably (McCormick, 2004, Bordowitz, 2003 and Flanagan, 1995) documents $U 2$ from a historical perspective while (Stokes, 2005) analyzes the artistic meaning behind $U 2$ 's music.

\section{METHODOLOGY}

An in depth historical analysis of the life of Bono and the journey of $U 2$ was conducted. The goal of this research was to determine if there were any themes that emerged which would benefit the careers of professionals and executives. Conclusions were formulated and are presented within the research.

\section{FINDINGS}

Upon conducting this research there are four (4) themes that have emerged. Below please find these themes and the reasons why executives would potentially benefit from them.

\section{Theme \#1 - The Power of Personal Tragedy}

Bono was born in the North Dublin suburb of Ballymun on May 10, 1960 and was the second son of Bob and Iris Hewson. (Koehn, Miller and Wilcox, 2009). Bono's father, a Catholic postal worker and his mother, a 
Protestant was considered an unusual arrangement for Sectarian Ireland at that time. (Fry, Bono Biography, U2 Official Website, 2010). Bono's only sibling, a brother Norman, is six years his senior.

Tragedy struck the Hewson's in September 1974 when Bono's mother, Iris, suffered a brain hemorrhage at her Father's funeral. She passed away four days later. Bono was only fourteen (14) at that time. (Koehn, Miller and Wilcox, 2009).

The death of Iris Hewson left Bono, his father and brother Norman alone in coping with the death of the central figure of their family. While Bob Hewson did the best he could at holding the family together, his coping mechanism was to stop talking about his wife, Iris, completely, leaving a strategic void within their home as well as few memories of her. (Koehn, Miller and Wilcox, 2009). Bono has indicated that the three remaining Hewsons' grief often times turned into rage causing violent conflicts among all of them. His house, as he has stated at that time, "ceased being a home." (U2 by U2, 2006, p. 18).

A tragedy, such as an unexpected death, ignites various responses from the surrounding loved ones. To some, it can paralyze them destroying one's hopes and dreams. To Bob Hewson, this was the case as Bono has stated his "unspoken message to his children was 'to dream is to be disappointed.' "(Fry, 2010).

To others, a tragedy such as a death of a loved one can be that moment of truth in one's life. Research has indicated that a tragedy and/or setback can be the impetus to ignite future greatness in one's life. (Lowney, 2009).

To Bono, this would be the case. Bono has often cited that his father's unspoken message about "not to dream" has propelled him to dream even more and to be more determined than ever with his ambitions. (Fry, 2010).

With this as a background, the question one must ask is how can this lesson help executives? Overall, this can be quite helpful in a variety of ways. First, it allows executives the opportunity to reflect on one's own life. Everyone experiences some form of tragedy and setbacks along the way. The question is how did one respond, in retrospect, to a specific situation? Did a tragedy or setback stifle a journey or did it provide strength and resolve for new challenges and accomplishments?

Secondly, such a lesson can also enhance one's own coaching abilities with staff and direct reports. If a direct report unexpectedly confronts a tragedy or setback, one as a supervisor and mentor can potentially provide advice and strength to ignite future greatness in one's life.

\section{Theme \#2 - The Power of the Instinctive Gut}

In business it has been noted that formulating a strategy and implementing it strategically and effectively is the key to success. Organizations can spend a countless amount of time researching, planning and developing a strategy either to, for example, develop a new product or service or to penetrate a new market. One of the oldest premises in business is that planned actions lead to desirable results.

This is exactly the opposite of what Bono did on July 13, 1985 during the Live AID Concert Event at Wembley Stadium. Live AID was an international concert event with a goal to raise funds and promote awareness for famine relief in Ethiopia. There were various concerts, on this day, held all over the world, at venues including London, Philadelphia, Sydney and Moscow. (Koehn, Miller and Wilcox, July 2009). While U2 was recently dubbed "Band of the Year" by a major publication, they were still not considered an international music sensation. (Koehn, Miller and Wilcox, July 2009).

Each band during the Live Aid event was given a fifteen (15) minute time slot to perform. As part of the predetermined strategy, $U 2$ planned on playing three (3) songs during their set including "Sunday Bloody Sunday", "Bad", and "Pride". Yet during the performance while playing their second song "Bad", Bono decided to steer away from the predetermined strategy and follow his instinctive gut. More specifically, he thought it would play well in front of a television audience if he jumped off stage and dance with a girl which he did. Yet in doing so he used up too many valuable minutes of the set which only enabled the band to play two songs during the performance. 
(Koehn, Miller and Wilcox, July 2009). While the other band members as well as U2's manager Paul McGuinness were initially furious at Bono for not following the predetermined strategy, in hindsight, it was a brilliant move as according to reviews and periodicals, it indicated that " $U 2$ stole the show" and as a result became an international music sensation that day forward. (Koehn, Miller and Wilcox, July 2009).

When looking at this example, executives must ask, once again, what can one learn from it? The research has illustrated that following one's instinctive gut, while risky, can allow for a historic moment within one's career and/or brand development. (Kiev, 2009). Gut instinct decisions are traditionally made when either not enough research and/or information are available or a thorough analysis of all the options and their repercussions are not fully evaluated.

Yet there are some very strong proponents of following one's gut instinct. During a Stanford University Entrepreneurial Thought Leader Lecture, Mr. Jeff Hawkins, the founder of Palm Computing and the inventor of Palm Pilot, has stated that focus groups and customer feedback can provide useful insight however one must listen to one's gut instinct even if the market research states otherwise. (Hawkins, 2009). In addition, there exists innovation experts who have stated similar thoughts when it comes to innovation and new product development. (Kuczmarski, 2005).

Overall, Bono's gut instinct decision during Live Aid was a critical moment for U2. Executives should realize that sometimes following one's gut instinct could lead to big results as what occurred with $U 2$ at Live Aid.

\section{Theme \#3 - The Power of Branding Beyond One's Core Competency}

Plain and simple, the core competency of any rock and roll band is to produce music and therefore the core competency of the lead vocal is to sing the music. The band $U 2$ has been together since 1977 and per all the awards they have received (as stated earlier) they have been quite successful with their core competency.

However, when one thinks about $U 2$ and Bono, one does not think about just the music. More specifically, Bono and $U 2$ represent a band and individuals who have been committed to social justice and humanitarian issues such as famine relief, Anti-Apartheid, debt forgiveness, and disaster relief for over a twenty five (25) year period. (Petit, 2010). The band and more specifically Bono have either been actively involved or spearheaded global initiatives such as Band Aid, Live Aid, Sun City, DATA (Debt, AIDS, Trade, Africa), Live 8, Jubilee 2000 and "Miss Sarajevo". (Petit, 2010). As stated earlier, Bono has earned a host of awards, recognition and positive press such as Time Magazine's Persons of the Year (alongside Bill and Melinda Gates) for his work and vocation in this area. (Fry, 2010). In addition, the lyrics that Bono creates when composing U2's music often times deals with religious, personal faith and political issues.

As one can see, Bono and the $U 2$ "brand" means so much more than just the music. (Koehn, Miller and Wilcox, July 2009). More specifically, Bono and $U 2$ have been all about "corporate social responsibility" before it became the "new buzzword" in business. (Petit, 2010).

After reading this, one is once again at the point of asking how can such a strategy of branding oneself beyond one's core competency help executives? In $U 2$ 's case, the strategy has paid dividends.

When the band first started in 1977, they were only fourteen, fifteen and sixteen years old. None of "these boys" had any serious musical training except for Larry Mullin Jr. who had taken drum lessons. (U2 by U2, 2006). Because Bono did not own an instrument, he became the lead singer by default. In essence, it was not about the unique pitch of his voice (U2 by U2, 2006). Bono even showed up at the first rehearsal on the back of someone's bicycle which illustrates where he and the group were at that point of their lives. (Koehn, Miller and Wilcox, July 2009).

Overall, during the initial stages of the group the band learned to play their musical instruments together. ( $U 2$ by $U 2,2006$ ). With this as a backdrop, the bottom line is that while $U 2$ does have a unique sound, it is difficult to argue that they are the best musicians ever to perform in a rock and roll band. 
The reason for this, besides their multiple awards and their longevity, is that $U 2$ provides something additional beyond the music. Within this "experience economy" there is a consumer expectation that the features and benefits of any product in question meets a certain standard. (Schmitt, 2004). In the case of a rock and roll band, the features and benefits of the product is the music itself.

However, $U 2$ has branded itself beyond the music positioning themselves as a spiritual group of musicians with a heart for the less fortunate. (Koehn, Miller and Wilcox, July 2009). While every album, and every artistic venture may have not received the same commercial success, $U 2$ has found a way to create a distinct position within the marketplace. Such a lesson is certainly an interesting one for professionals and executives who are looking to create a unique position within the marketplace within this "experience economy."

\section{Theme \#4 - The Power of Being Real}

From nearly the beginning of their existence, $U 2$ and more specifically Bono have "cultivated a reputation for being able to connect physically and emotionally with fans to an astonishing degree during the band's performances." (Fry, 2010). Bono has been known during performances and concerts to dance with girls, sip fan's beer and wine and walk on tables. He has also sprayed fans with champagne, filmed them with their video cameras and has given group hugs. Overall, $U 2$ and more specifically Bono have developed a reputation of "heartfelt and profound love for its audience." (Fry, 2010).

On March 6, 2009, U2 performed on the Good Morning America set at Fordham University's campus in the Bronx, New York. Ms. Robin Roberts, the anchor of Good Morning America, profoundly stated that U2 and Bono are "all about the people" when Bono requested a microphone during an interview so that all the students present could listen in.

Overall, in addition to connecting with the audience (i.e. stakeholders), Bono has portrayed himself as a sensitive and "real" individual. There seems to be no mystery to his feelings and no mask to his persona which has led audiences and fans to love him or despise him all the more.

Executives could benefit quite a bit with Bono's approach. While one's counterparts and direct reports will not necessarily agree with you at all times, these individuals will certainly appreciate colleagues who are real and whose primary concern is for the customer. Human beings need to connect with one another at a deep level. Bono's approach has certainly allowed for this to occur with his stakeholders.

\section{CONCLUSION}

The purpose of this study was to conduct a historical analysis of the life of Paul David Hewson (aka Bono) with the hopes of uncovering key learning points and takeaways that executives could apply within their professional roles. Upon conducting this research it became apparent that there are four (4) overarching themes that executives can learn from Bono. They are as follows: (1) The Power of Personal Tragedy; (2) The Power of the Instinctive Gut; (3) The Power of Branding Beyond One's Core Competency; and (4) The Power of Being Real. As stated within this research, these takeaways are a result of the decisions Bono has made throughout his life. In closing, the goal of this initial study was not only to illustrate key learning points executives can take away from Bono but to also ignite increased research and interest on Bono and the " $U 2$ Effect."

\section{AUTHOR INFORMATION}

Francis Petit is the Associate Dean for Executive MBA Programs at Fordham University Graduate School of Business Administration. In his overall work with executive students, Dr. Petit has established executive programs in North America, South America, Europe, Asia and the Middle East. He holds a Doctorate in Economics and Education from Columbia University and serves as an Adjunct Associate Professor of Marketing at Fordham University. E-mail: petit@fordham.edu 


\section{REFERENCES}

1. Bono, The Edge, Clayton, Adam and Mullin, Larry Jr. (With Neil McCormick) (2006). U2 by U2, itbooks (an imprint of Harper Collins Publishers), pp. 29-293.

2. Flanagan, Bill (1995), U2 At The End of the World, Bantam Press, London.

3. Fry, Maddy (2010), "Bono Biography", U2 Official Website (http://www.u2.com ).

4. Kiev, Ari (2009), The Mental Strategies of Top Traders: The Psychological Determinants of Trading Success, Wiley Trading.

5. Koehn, Nancy, F., Miller, Katherine and Wilcox, Rachel K. (2009), Bono and U2, Harvard Business School, Massachusetts, pp. 1-41.

6. Kuczmarski, Thomas D. (2005), Innovation: Leadership Strategies for the Competitive Advantage, Book Ends Publishing, Chicago, IL, pp. 1-83.

7. $\quad$ Lowney, Christopher (2009), Heroic Living, Loyola Press, Chicago, IL.

8. $\quad$ McCormick (2004), I Was Bono's Doppelganger, London: Penguin Books, pp. 10-41.

9. Petit, Francis (2010). "What Executives Can Learn From U2", Review of Business and Finance Case Studied. The Institute for Business \& Finance Research, Hilo, HI.

10. $\quad$ Schmitt, Bernd (2004), Customer Experience Management, Wiley, pp. 1-89.

11. Stanford University Entrepreneurial Thought Leader Lectures (2009), Jeff Hawkins.

12. Stokes, Niall (2005), U2 Into the Heart: The Stories Behind Every Song, Thunder's Mouth Press, New York.

13. The U2 Reader: A Quarter Century of Commentary, Criticism and Reviews, ed. Hank Bordowitz (2003), Milwaukee, WI, Hal Leonard Corporation.

14. U2: Rattle and Hum (1988 Documentary)

15. U2 Tops Billboards Money Maker’s Chart, January 20, 2006. (Accessed @ www.factiva.com). 